\title{
TENTOONSTELLING \\ Handelswaar en Souvenirs - islamitische kunst uit het Rijksmuseum Amsterdam
}

Een Algerijnse sabel uit het bezit van Michiel de Ruyter, een Indiase miniatuur, een 'Pools tapijt', een aardewerken schaal uit Perzië - diverse kunstvoorwerpen die op het eerste gezicht niets met elkaar te maken hebben. Toch is er een rode draad die al deze objecten verbindt: ze zijn allemaal ontstaan in gebieden waar de islam een belangrijke politieke of culturele rol speelt of heeft gespeeld. Ruim 170 objecten, voornamelijk uit het Rijksmuseum Amsterdam, zijn naar Leiden gehaald, waaronder een aantal unieke stukken die dankzij deze tentoonstelling getoond kunnen worden na jarenlang in het depot te hebben gestaan.

Meteen na het binnengaan ziet de bezoeker zo'n lang verborgen schat: een Iraans tapijt uit de $17^{c}$ eeuw. Meer dan zes meter lang en met een prachtige kleurcombinatie van geel, groen en rood, het maakt een diepe indruk. Daartegenover hangen nog twee beeldschone tapijten, deze keer uit Turkije, in zwart en rood. Vooral het rood is erg goed bewaard gebleven, nog steeds diep en warm, hoewel ook deze tapijten uit de $17^{\mathrm{e}}$ eeuw stammen.

In de tweede zaal staat een van mijn favorieten: een aardewerken kom met kalligrafie aan de binnenkant (afb. 1; ook op de tentoonstellingsposter te zien). Herkomst: de stad Nishapur in het huidige Iran. De grote, gestileerde letters in het zwart zijn goed te zien op de crèmekleurige achtergrond. Het effect is wonderschoon. De binnenkant is glad en zacht, het glanst. Ik krijg zin om de kom aan te raken, om mijn vingers over de letters te laten bewegen. Gelukkig staat hij veilig in de vitrine.

Kalligrafie speelt een belangrijke rol in de islamitische kunst. Aardewerk, tegels en zelfs textiel werden van kalligrafie voorzien. Het zijn vooral Koranfragmenten, soms ook spreuken en gelukswensen. Maar behalve als drager van informatie, heeft de kalligrafie ook een esthetische functie gehad. De zojuist besproken kom uit Nishapur is daar een goed voorbeeld van. Soms zijn de letters zo gestileerd dat zelfs specialisten moeite hebben om ze te interpreteren, maar het idee dat ze toch een verborgen boodschap bevatten maakt zulke objecten nog meer bijzonder: het is een kunstwerk met een geheim.

Dit geheim, deze 'verborgen boodschap', sprak het westerse publiek blijkbaar erg aan. Europese kunstwerken werden vaak met Arabische kalligrafie of pseudo-kalligrafie versierd. Dit is onder andere goed zichtbaar in de toegepaste kunst uit de $19^{c}$ eeuw en brengt ons bij een van de hoofdthema's die in deze tentoonstelling centraal staat: de wederzijdse beïnvloeding tussen de Westerse en Oosterse handwerklieden. Vooral de textielfragmenten laten deze wederzijdse beïnvloeding goed zien: veel gebruikte decoratieve motieven 


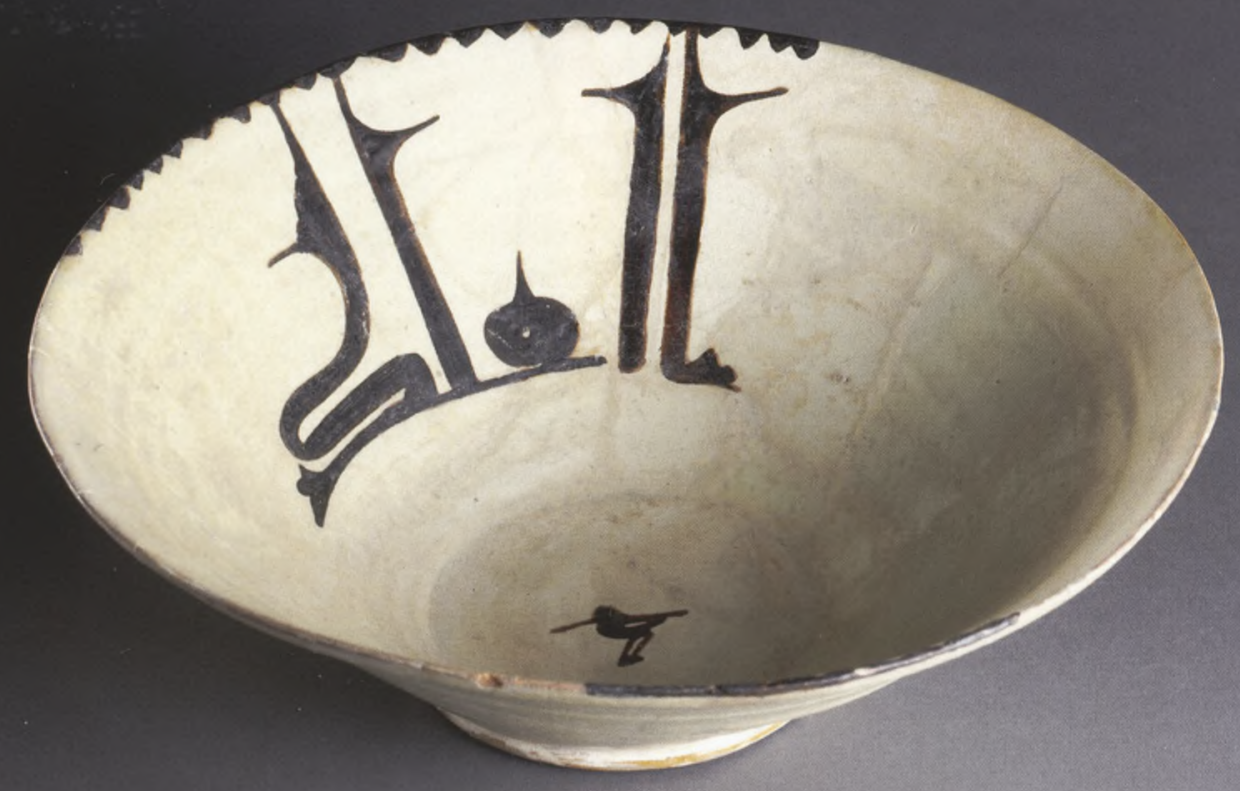

Afb. 1

Kom van aardewerk.

Nishapur, 10' eeuw.

Schenking van de heer

en mevrouw

Oosterbaan-Lugt.

BK-1981-56. in Italiaanse en Spaanse weefsels, zoals de gepaarde adelaars en gevleugelde draken met hondenkoppen (afb. 3), gaan terug op Perzische en Byzantijnse voorbeelden. De motieven werden eerst erg populair in de grensgebieden, zoals Sicilië en Spanje, en daarna ook in andere landen rondom de Middellandse Zee. Ongeveer vanaf de $13^{\mathrm{e}}$ eeuw kan men van een internationale stijl spreken, aangezien de weefsels zo op elkaar lijken dat het moeilijk te bepalen is waar ze precies vandaan komen.

Ook de Arabische kunstenaars zochten vaak hun inspiratie buiten hun directe omgeving: in Westerse en pre-islamitische motieven. Om vooral dit laatste te illustreren werd de tentoonstelling verrijkt met een aantal archeologische objecten uit de collectie van het Rijksmuseum van Oudheden (RMO), zoals glazen parfumflesjes, aardewerk afkomstig uit het gebied rond de Kaspische Zee, en Koptisch textiel.

Een tentoonstelling over islamitische kunst kan niet compleet zijn zonder beschilderde tegels en miniatuurschilderkunst. Beide zijn in het RMO te zien. Een kleine, maar zorgvuldig uitgekozen groep Perzische en Indiase miniaturen hangt rechts van de ingang. Door hun rijkdom aan kleuren en de minutieus uitgewerkte details zijn ze een ware lust voor het oog. De miniatuurschilderkunst heeft India via Perzië bereikt en de islamitische access 


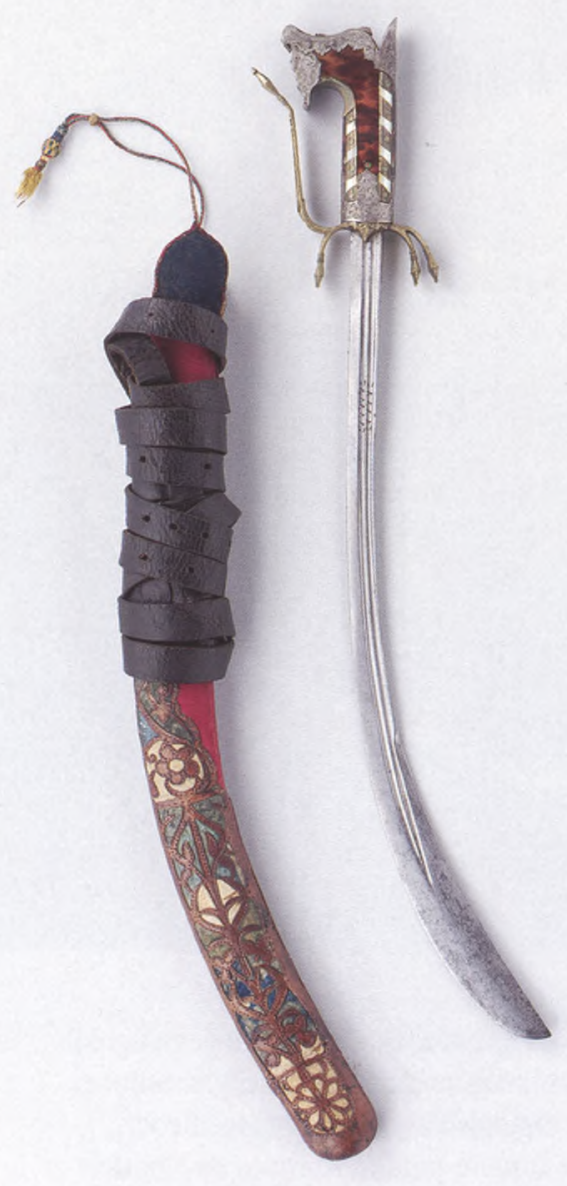

Afb. 2 (links)

De nimcha van Michiel de Ruyter. Algerije,

\section{$17^{e}$ eeuw.}

NG-NM-10412.

Afb. 3

\section{Fragment van een} zijdeweefsel. Lucca of Spanje, $13^{e}$ eeuw. BK-NM-1211.

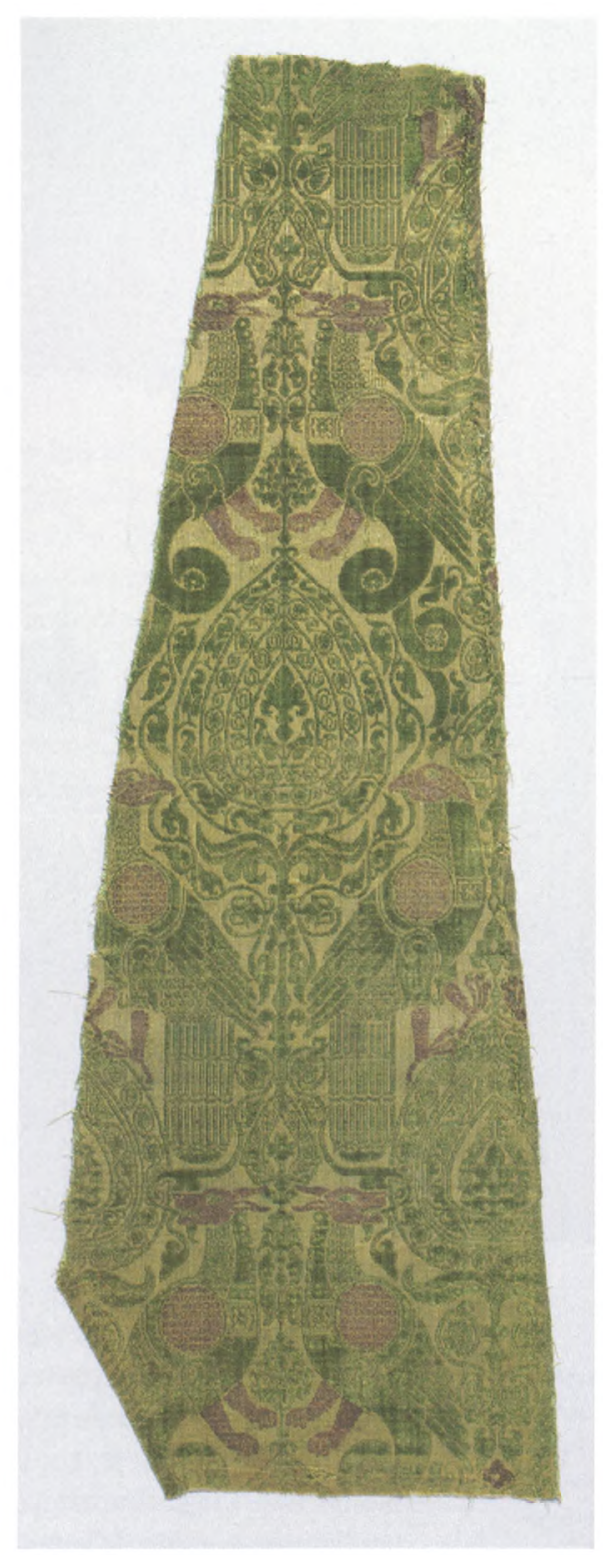

Mogol-keizers hebben er een hofkunst van gemaakt. Een van de belangrijke bijdragen van de Mogol-kunst was de introductie van een realistische portretweergave, iets wat in de eerdere Indiase schilderkunst niet of nauwelijks aanwezig was. Vooral het atelier van de keizer Akbar (r. 15561605) speelde hier een grote rol.

Hoewel de stijlen van de Perzische en de Mogol-miniaturen helemaal eigen zijn, zijn de afgebeelde thema's in de hele islamitische cultuurwereld bekend, zoals het verhaal over de liefde tussen Laila en Majnun (afb. 4). Andere scènes zijn ook voor de Westerse bezoeker niet vreemd: Abraham en het offer van Izaac ( $a f b .5$ ), en het verhaal van Jozef en zijn broers, die hier vorm gekregen hebben in twee Perzische miniaturen. 

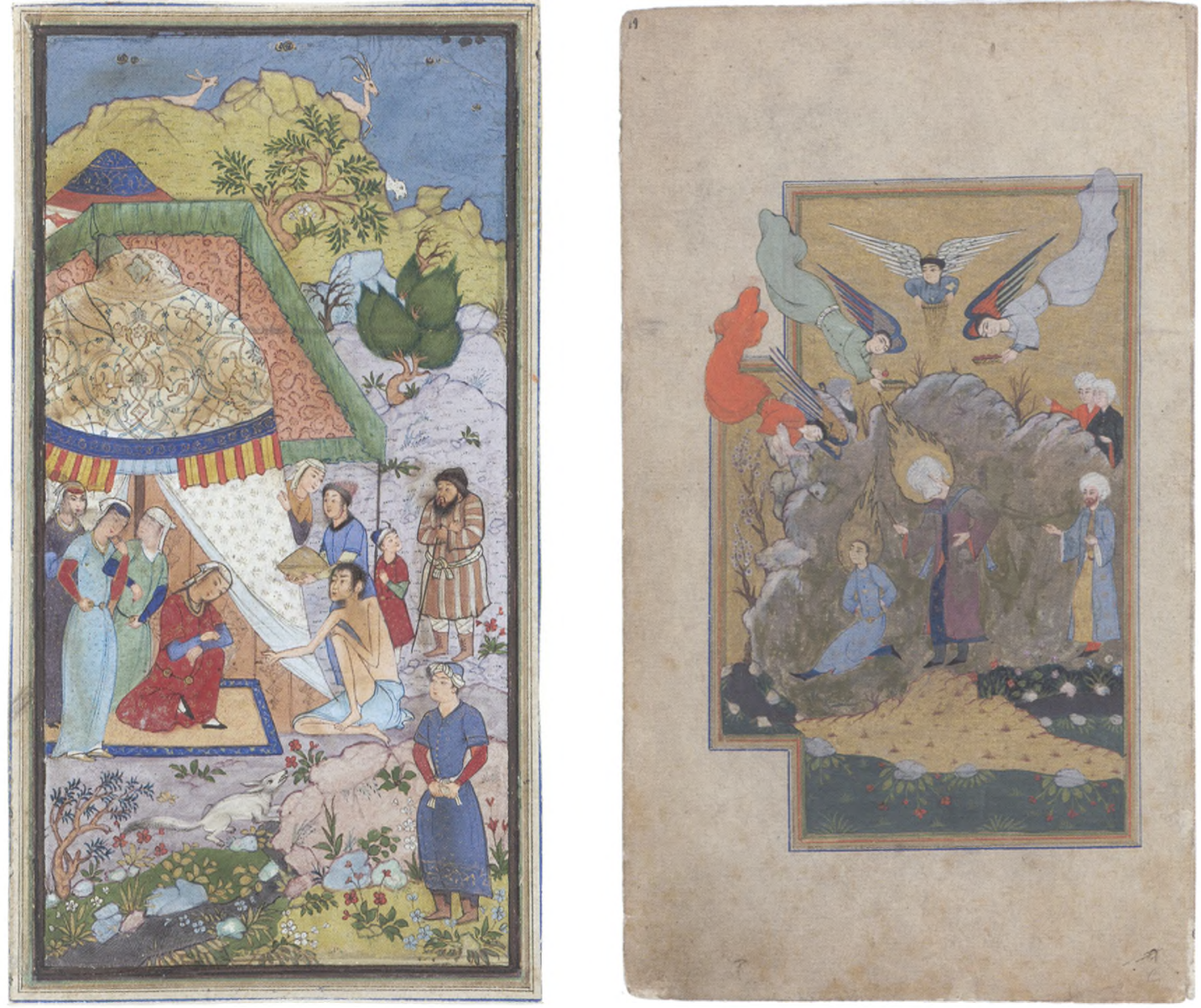

Afb. 4 (links) Illustratie uit het verhaal van Laila en Majnun. Perziè, $16^{e}$ eeuw. AK-MAK-1251.

Afb. 5 Abraham en het offer van Izaak. Perziě, $16^{e}$ eeuw. Schenking van de heer $P$. Formijne. RP-T-1993-460.
De tentoonstelling met zijn zeer gevarieerde kunstobjecten is zeker een verrassing voor bezoekers die het Rijksmuseum vooral van de Nachtwacht en het Melkmeisje kennen (lezers van Aziatische Kunst vormen hier natuurlijk een uitzondering op!). En inderdaad, islamitische kunst is min of meer toevallig in de collectie van het Rijksmuseum terechtgekomen, vaak als handelswaar of souvenir zoals de titel van de tentoonstelling suggereert. $\mathrm{Al}$ in de $17^{\mathrm{e}}$ eeuw handelden Nederlanders in oosterse textiel en tapijten. In deze tijd hebben ook de leden van de VOC de eerste miniatuurschilderingen uit India naar Amsterdam gebracht. De aan het begin genoemde fraaie Algerijnse sabel, de nimcha, veroverde Michiel de Ruyter op een Algerijnse zeerover men kan hier zeker van een bijzonder souvenir spreken (afb. 2)!

De tentoonstelling in Leiden is een uiting van de over de laatste paar jaar groeiende interesse in de islamitische cultuur in Nederland - zoals het succes van onder andere de tentoonstellingen Passie voor perfectie en daarvoor van Oman in De Nieuwe Kerk heeft bewezen - maar ook daarbuiten. Er zijn recentelijk twee belangrijke wereldmusea voor islamitische kunst geopend: in Toronto en in Doha. Ook de resultaten van een veiling bij Sotheby's, Londen, op 6 april van dit jaar, laten deze belangstelling zien: een geillustreerd bląd uit het Shah-nama (het Boek der Koningen; Perzië, circa 1525-1535) werdree access 


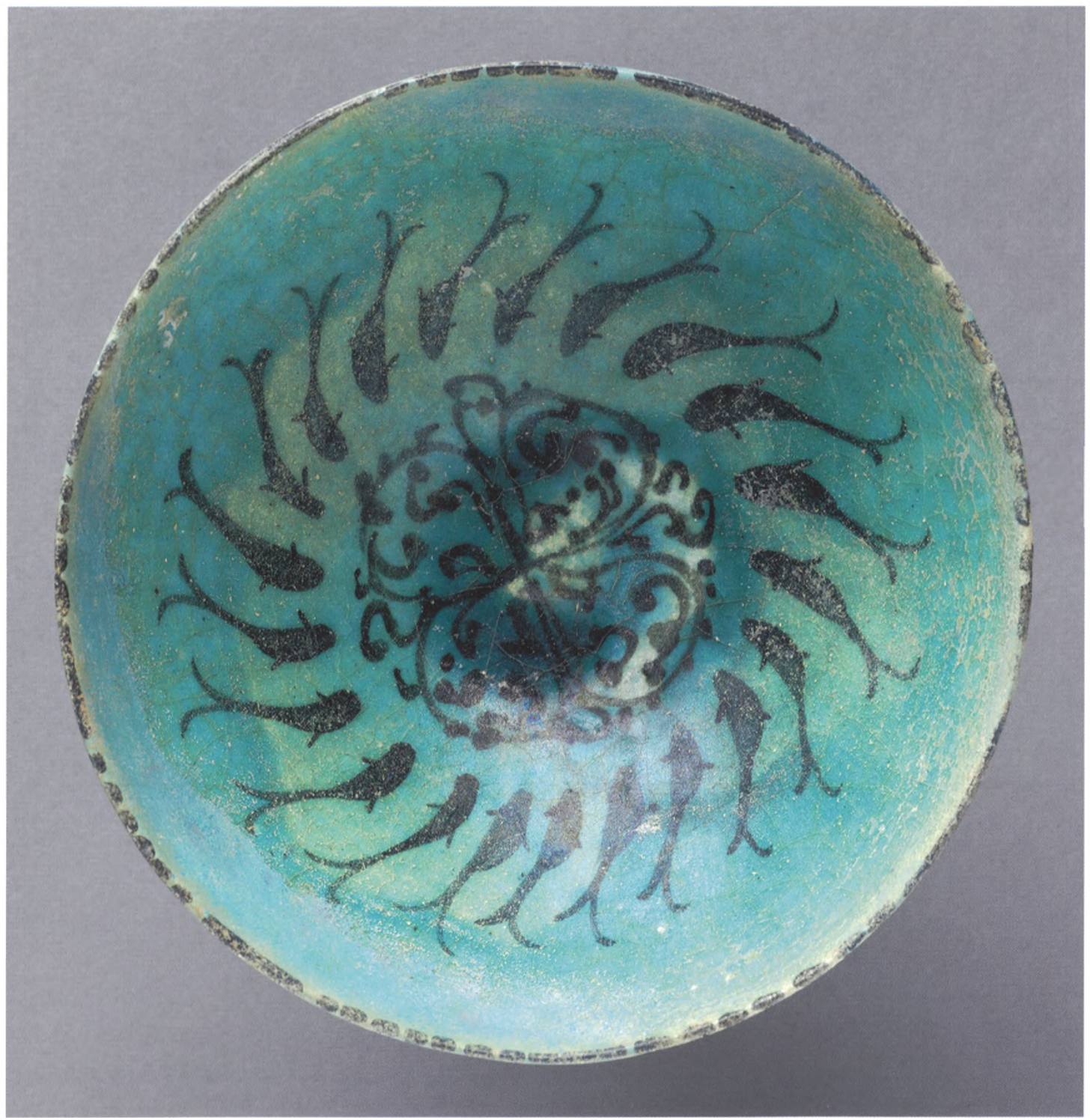

Afb. 6

Kom. Perziē, $13^{\mathrm{e}}$ eeuw.

Legaat van de heer en

mevrouw Oosterbaan-

Lugt. BK-2000-63-C. 
voor bijna 7,5 miljoen Britse pond verkocht. Maar wat is 'islamitische kunst' eigenlijk? Is deze zo vaak gebruikte term eigenlijk wel correct?

De voorwerpen die, wat functie of decoratie betreft, een duidelijke link met de islam tonen, kunnen zeker als 'islamitische kunst' bestempeld worden. Maar deze term wordt ook met regelmaat gebruikt voor objecten met een seculiere functie die in een lokale stijl vervaardigd zijn, en die moeilijk als een algemene 'islamitische stijl' betiteld kan worden. Bovendien wordt de term gebruikt voor objecten gemaakt door en voor mensen die geen moslims zijn, maar die wonen of woonden in gebieden waar moslims de meerderheid vormden. Of waar de heersers moslims zijn of waren. Zijn de Perzische kommen met turkoois-blauw glazuur - een prachtige collectie overigens - die in de tentoonstelling te zien zijn, eigenlijk 'islamitisch' (afb. 6)? En wat is er islamitisch aan de eerder genoemde Italiaanse weefsels, behalve dat de gebruikte motieven een Perzische of Byzantijnse kunst als herkomst hebben? Het contrast met het gebruik van de termen 'christelijke kunst' of 'boeddhistische kunst' is hier duidelijk te zien. Deze controverse is door vele kunsthistorici en Arabisten opgemerkt, onder andere door Mirjam Shatanawi die in haar boek Islam in beeld een hele discussie eraan wijdt, en tevens door de conservator van de tentoonstelling. ${ }^{1}$ Toch werd er gekozen om deze term in de titel van de tentoonstelling op te nemen. Zelf zou ik liever over 'kunst van de islamitische wereld' spreken. Dit is zeker geen ideale oplossing, maar deze beschrijving suggereert tenminste niet dat het hier uitsluitend om religieuze kunst gaat. Misschien is de tentoonstelling in het RMO, behalve een lust voor het oog, ook een mooie aanleiding om de discussie over deze terminologie een nieuw leven in te blazen.

De tentoonstelling Handelswaar en Souvenirs - islamitische kunst uit het Rijksmuseum Amsterdam is te zien van 21 maart tot 4 september 2011, in Rijksmuseum van Oudheden te Leiden.

* Dr. Anna Slaczka is conservator Indiase kunst bij het Rijksmuseum. Zij promoveerde (2006) in Leiden op het gebied van Sanskrit en Indiase kunst. Ze richt zich momenteel op contacten tussen Zuid- en Zuidoost-Azië, iconografische Sanskritteksten, kunst en architectuur van India en hindoetempelrituelen. Als conservator Indiase kunst is Anna Slaczka tevens verantwoordelijk voor de (islamitische) Mogol-kunst uit India.

\section{Literatuur}

The Rijksmuseum Bulletin, 59/1 (2011) - het hele nummer is gewijd aan de kunst getoond in de tentoonstelling, met artikelen van Jan de Hond, Luitgard Mols, Eveline Sint-Nicolaas, Jef Teske, Agnita van 't Klooster en Friedrich Spuhler. Mirjam Shatanawi, Islam in beeld: Kunst en cultuur van moslims wereldwijd, Amsterdam, 2009.

\section{Noot}

1. Shatanawi, M, Islam in beeld, 2009, pp. 25-32.

Jan de Hond, The Rijksmuseum Bulletin 59/1 (2011), p. 5. 